\title{
DIVULGAÇÃO DE INFORMAÇÕES AMBIENTAIS NAS DEMONSTRAÇÕES CONTÁBEIS: UM ESTUDO EXPLORATÓRIO SOBRE O DISCLOSURE DAS EMPRESAS BRASILEIRAS PERTENCENTES A SETORES DE ALTO IMPACTO AMBIENTAL
}

\author{
SULIANI ROVER \\ Graduada em Ciências Contábeis pela \\ Universidade Federal de Santa Catarina \\ E-mail: sulianirover@yahoo.com.br \\ JOSÉ ALONSO BORBA \\ Doutor em Controladoria e Contabilidade pela \\ Universidade de São Paulo \\ Professor da Universidade Federal de Santa Catarina \\ E-mail: jalonso@cse.ufsc.br
}

\author{
FERNANDO DAL-RI MURCIA \\ Mestre em Contabilidade pela \\ Universidade Federal de Santa Catarina \\ E-mail: murcia77@gmail.com \\ ERNESTO FERNANDO RODRIGUES VICENTE \\ Doutor em Administração pela \\ Universidade de São Paulo \\ Professor Adjunto da Universidade Federal \\ de Santa Catarina \\ E-mail: e.fernando@cse.ufsc.br
}

\section{Resumo}

O objetivo deste trabalho é examinar as informações ambientais divulgadas voluntariamente pelas empresas brasileiras. O levantamento dessas informações foi realizado a partir das Demonstrações Financeiras Padronizadas (DFPs) de 2006. A técnica utilizada foi a análise de conteúdo, sendo que optou-se pelo número de sentenças como unidade de registro. A amostra do estudo consiste nas empresas listadas na Bolsa de Valores de São Paulo (BOVESPA), e pertencentes a setores de alto impacto ambiental segundo a Lei $n^{\circ} .10 .165 / 2000$, que dispõe sobre a Política Nacional do Meio Ambiente. Os resultados evidenciam que a categoria com maior número de sentenças é a de "Políticas Ambientais", seguida pela de "Informações Financeiras Ambientais". A maioria das informações é declarativa, do tipo positiva, localizada no Relatório da Administração e não auditada. Esses resultados corroboram a Teoria do Disclosure Voluntário e os estudos anteriores, na medida em que não se esperava que as empresas divulgassem voluntariamente informações negativas a respeito de suas práticas ambientais.

Palavras-chave: disclosure ambiental; demonstrações contábeis; meio-ambiente.

\begin{abstract}
The objective of this paper is to examine the environmental information voluntarily published by Brazilian companies. The survey on this information was carried out from the financial demonstrations patterns (FIPs) in 2006. The used technique was the content analysis taken by choosing the number of sentences as a registered unit. The sample for this study consists of companies listed in Sao Paulo stock market (BOVESPA) and belonging to high environmental impact sectors according to law number $10.165 / 2000$ that states about the national environmental policy. The results show that the group having the highest number of sentences is the 'Environment Policies', followed by 'Environmental Finance Information'. Most of the information is declarative, of positive kind, placed in the administration report but not audited. These results comply with the Theory of Voluntary Disclosure and with previous studies, considering that the companies were not expected to voluntarily publish negative information about their environmental practices.
\end{abstract}

Key words: environmental disclosure, accounting demonstrations, environment. 


\section{INTRODUÇÃO}

A partir de uma perspectiva informacional, a divulgação das Demonstrações Contábeis visa prover aos usuários externos informações relevantes para a tomada de decisão (BEAVER, 1998). Nessa ótica, um dos principais objetivos da informação contábil é contribuir para a redução da assimetria informacional existente entre os usuários internos (gestores, executivos etc.) e os usuários externos da entidade (acionistas, credores, governo etc.) (LOPES \& MARTINS, 2005).

Dentro do escopo das diversas informações divulgadas pelas entidades, encontramse as informações de caráter ambiental. Apesar de existirem tentativas de normatizar a forma pela qual as informações sociais e ambientais devem ser evidenciadas, como são os casos dos modelos de Balanço Social do Instituto Brasileiro de Análises Sociais e Econômicas (IBASE) e do Global Reporting Initiative (GRI), não há no Brasil nenhuma obrigatoriedade na divulgação dessas informações.

Nota-se que, apesar de não existir lei ou norma específica que obrigue as empresas a evidenciar informações ambientais, muitas delas o fazem. Obviamente, a preparação e divulgação destas informações geram custos adicionais e muitas vezes tornam públicas informações estratégicas aos concorrentes. (SOLOMON \& SOLOMON, 2004). Por outro lado, a divulgação de informações voluntárias também pode trazer benefícios às empresas como, por exemplo, a redução do custo de capital, o aumento da liquidez das ações e a criação de uma imagem ambientalmente correta.

De maneira geral, espera-se que os benefícios gerados pela divulgação de informação não-obrigatória sejam superiores aos seus custos (DYE, 2001). Segundo Gray et al. (2001) também é possível enxergar o disclosure voluntário, no qual se inserem as informações ambientais, como uma forma de redução dos custos de agência.

Dentro deste cenário, se o objetivo do gestor é maximizar o valor da firma e existem custos associados com a preparação e divulgação das informações, parece haver um equilíbrio onde a informação que favorece a firma é evidenciada, enquanto a que prejudica não é evidenciada (VERRECCHIA, 2001). De acordo com a Teoria do Disclosure Voluntário, a entidade tende a divulgar voluntariamente apenas informações positivas (DYE, 2001).

Contudo, devido ao risco de seleção adversa, as empresas podem também evidenciar informações negativas de maneira voluntária quando acreditarem que serão penalizadas pelos usuários externos caso não as divulguem. Dada a possibilidade de haver atributos não evidenciados, acionistas podem preferir não investir em empresas que não apresentam voluntariamente informações de natureza ambiental (BRAMMER \& PAVELIN, 2006). Segundo Verrecchia (2001), o investidor racional interpreta a informação não divulgada como uma informação não favorável.

Dentro da linha de estudos que busca compreender o disclosure voluntário, o presente trabalho tem como objetivo examinar as informações de caráter ambiental divulgadas voluntariamente pelas empresas brasileiras. A justificativa para condução desta pesquisa baseia-se em duas premissas essenciais para a realização de um trabalho científico: a crescente demanda da sociedade por maior accountability no que tange a relação das empresas com o meio ambiente e a escassez de literatura acerca do tema evidenciação ambiental no cenário brasileiro.

De acordo com Labatt e White (2002) a atenção acerca da gestão ambiental tem crescido em praticamente todos os segmentos do mercado. Nesse sentido, as empresas são cada vez mais exigidas a contribuir para o desenvolvimento econômico sustentável 
(PINTO \& RIBEIRO, 2004). Logo, as organizações estão incorporando procedimentos que minimizam impactos sobre a natureza, tais como: mecanismos para a diminuição de emissão de efluentes líquidos e gasosos, reciclagem de materiais etc. (NOSSA, 2002). Nessa mesma linha de pensamento, Ribeiro e Martins (1993) ressaltam que a Contabilidade deverá aparelhar-se para satisfazer os usuários interessados na atuação das empresas sobre o meio ambiente, tendo em vista o dever de subsidiar o processo de tomada de decisão.

Do mesmo modo, a maioria dos estudos acerca da divulgação de informações ambientais utiliza amostras de empresas de países desenvolvidos (TSANG, 1998). Segundo Newson e Deegan (2002) a grande parte dos estudos é realizada nos Estados Unidos, Europa e Austrália. Assim, a pesquisa acerca da evidenciação de informações ambientais e sociais é extremamente necessária em países menos desenvolvidos, visto a presença de empresas multinacionais nesses países (GRAY; OWEN \& ADAMS, 1996).

Nessa ótica, a falta de estudos em países menos desenvolvidos representa uma justificativa para realização deste estudo. 0 trabalho de Gallon et al. (2007) que examinou os artigos científicos da temática ambiental no período de 2000 a 2006, constatou que a área específica de disclosure ambiental representa menos de $10 \%$ do total de artigos analisados. De acordo com os resultados desta pesquisa, os estudos brasileiros estão concentrados principalmente na área de gestão ambiental e de sustentabilidade.

Finalmente, a pesquisa permite a interação da Contabilidade com outras áreas do conhecimento, relacionadas ao meio ambiente. Assim, justifica-se a realização desta pesquisa, possuidora de tema multidisciplinar e relevante para a prática organizacional, todavia pouco abordado pela comunidade científica nacional.

Para abordar os apontamentos esboçados até então, estruturou-se o trabalho em mais quatro seções, além desta breve introdução. A seção 2 apresenta o referencial teórico sobre divulgação de informações ambientais e estudos relacionados. Na seção 3 descrevem-se os aspectos metodológicos e as delimitações do trabalho. A seção 4 evidencia os resultados das análises do estudo e a seção 5 apresenta os aspectos conclusivos e recomendações para futuras pesquisas.

\section{FUNDAMENTAÇÃO TEÓRICA}

Apesar da evidenciação de informações ambientais, também conhecida como "green reporting", diferir do escopo tradicional da Contabilidade focado nas informações de natureza econômico-financeira (Demonstração do Resultado do Exercício, Balanço Patrimonial, Demonstração das Origens e Aplicações de Recursos, Demonstração do Fluxo de Caixa etc.), sua divulgação pode ser considerada relevante na medida em que eventos ambientais podem impactar também na saúde financeira de uma empresa (como, por exemplo, multas e passivos ambientais, investimentos etc.).

Segundo Ferreira (1995) existem vários exemplos de como a questão do meio ambiente pode impactar no resultado da empresa, no entanto, o que ainda não se sabe é como mensurá-los. Para Tinoco (1993) a sociedade merece ser informada sobre os esforços acerca das práticas ambientais e sociais das entidades, sendo sua divulgação positiva para as empresas, quer do ponto de vista de sua imagem, quer do ponto de vista da melhoria e qualificação da informação contábil/financeira.

De acordo com o arcabouço proposto por Deegan (2002), a pesquisa que aborda a evidenciação de informações ambientais pode ser enquadrada dentro de uma grande área chamada Social and Environmental Accounting Research (SEAR). Dentro dessa área 
também estariam incluídas as informações relativas à comunidade, aos funcionários e também à Demonstração do Valor Adicionado (DVA).

Apesar de incipiente no cenário nacional, a revisão de literatura evidenciou algumas pesquisas que tratam do tema divulgação de informações ambientais. Merece destaque o trabalho pioneiro de Nossa (2002) que investigou o disclosure ambiental das empresas brasileiras e estrangeiras do setor de papel e celulose. Seus resultados corroboram a teoria existente, uma vez que o disclosure ambiental varia de acordo com o tamanho da empresa e do país.

Utilizando também uma amostra de empresas do setor de papel e celulose, Costa e Marion (2007) examinaram o disclosure das informações ambientais disponibilizadas nos sites das empresas e da Bolsa de Valores de São Paulo (BOVESPA) e constataram que a falta de uniformidade prejudica a análise das informações.

Cunha e Ribeiro (2006) analisaram os fatores que determinavam a publicação do Balanço Social no Brasil. Os resultados evidenciaram que a divulgação voluntária de informações de natureza social está associada positivamente ao nível de governança corporativa e à divulgação em período anterior, e negativamente ao tamanho.

Borba, Rover e Murcia (2006) realizaram uma comparação entre o disclosure de informações ambientais divulgadas no Brasil e nos Estados Unidos. Para isso, os autores analisaram as empresas brasileiras listadas na New York Stock Exchange (NYSE). Os resultados indicaram que existe divergência entre o volume de informações divulgado no Brasil e nos Estados Unidos.

No cenário internacional, pode-se dizer que a área Social and Environmental Accounting Research (SEAR) encontra-se cientificamente mais desenvolvida. 0 periódico australiano "Accounting, Auditing and Accountability Journal", por exemplo, realizou duas edições especiais sobre esse tema: Social and Environmental Reporting (2002) e Ethical, Social and Environmental Accounting (2007). Neste sentido, diversos autores têm buscado realizar trabalhos acerca da divulgação de informações ambientais. O Quadro 1 ilustra algumas destas pesquisas. 


\begin{tabular}{|c|c|}
\hline Autor / Periódico & Pesquisa \\
\hline $\begin{array}{l}\text { Villiers e Staden }(2006) \\
\text { Accounting, Organization and } \\
\text { Society }\end{array}$ & $\begin{array}{l}\text { Utilizaram a Teoria da Legitimação para analisar a } \\
\text { evidenciação ambiental de uma amostra de } 140 \text { empresas Sul- } \\
\text { Africanas durante um período de nove anos. Os autores } \\
\text { concluíram que houve um aumento no volume evidenciado no } \\
\text { período de } 1994 \text { a } 1999 \text {, mas também uma redução do período } \\
\text { de } 2000 \text { a } 2002 \text {. }\end{array}$ \\
\hline $\begin{array}{l}\text { Coupland (2006) } \\
\text { Critical Perspectives on } \\
\text { Accounting }\end{array}$ & $\begin{array}{l}\text { Examinou os relatórios ambientais e sociais disponíveis nos } \\
\text { websites de cinco bancos do Reino Unido: Lloyds/TSB, The } \\
\text { Royal Bank of Scotland, HSBC, Barclays e Co-operative Bank. }\end{array}$ \\
\hline $\begin{array}{l}\text { Cowan e Gadenne (2005) } \\
\text { Journal of Accounting and } \\
\text { Organizational Change }\end{array}$ & $\begin{array}{l}\text { Compararam a evidenciação ambiental obrigatória com a } \\
\text { voluntária de } 25 \text { empresas australianas durante o período de } \\
1998-2000 \text {. Os autores concluíram que as informações } \\
\text { obrigatórias são mais negativas do que as voluntárias, o que } \\
\text { sugere a necessidade de elaboração de uma norma que } \\
\text { obrigue a divulgação. }\end{array}$ \\
\hline $\begin{array}{l}\text { O'Dwyer e Owen (2005) } \\
\text { The British Accounting Review }\end{array}$ & $\begin{array}{l}\text { Analisaram os Relatórios de Sustentabilidade de } 41 \text { empresas } \\
\text { do UK com o objetivo de verificar as características ao } \\
\text { processo de auditoria. Os resultados evidenciaram que existe } \\
\text { uma grande influência dos gestores no processo de auditoria o } \\
\text { que prejudica a credibilidade destes relatórios. }\end{array}$ \\
\hline $\begin{array}{l}\text { Kuasirikun e Sherer (2004) } \\
\text { Accounting, Auditing and } \\
\text { Accountability Journal }\end{array}$ & $\begin{array}{l}\text { Examinaram o disclosure ambiental e social de uma amostra } \\
\text { de empresas na Tailândia e constataram que a maioria das } \\
\text { informações é declarativa e evidenciada no Relatório de } \\
\text { Administração. }\end{array}$ \\
\hline $\begin{array}{l}\text { Al-Khater e Naser (2003) } \\
\text { Managerial Auditing Journal. }\end{array}$ & $\begin{array}{l}\text { Investigaram a percepção de usuários das Demonstrações } \\
\text { Contábeis no Catar, e constaram que os usuários são } \\
\text { favoráveis a evidenciação de informações de caráter social e } \\
\text { ambiental, pois acreditam que as empresas possuem } \\
\text { responsabilidade perante seus stakeholders que vai além da } \\
\text { maximização do valor do acionista. }\end{array}$ \\
\hline $\begin{array}{l}\text { Imam (2000) } \\
\text { Managerial Auditing Journal }\end{array}$ & $\begin{array}{l}\text { Analisou a evidenciação de informações de caráter ambiental } \\
\text { e social pelas empresas de Bangladesh. Seus resultados } \\
\text { indicaram que a grande maioria das informações é positiva, } \\
\text { descritiva (não monetária) e divulgada no Relatório da } \\
\text { Administração. }\end{array}$ \\
\hline
\end{tabular}

Quadro 1 - Estudos similares realizados no âmbito internacional

Com base nos estudos similares realizados no âmbito internacional, demonstrados no Quadro 1, percebe-se que a maioria das informações ambientais evidenciadas pelas empresas está localizada no Relatório da Administração, trazem uma notícia boa, possuem caráter declarativo (não monetário) e não são auditadas. Como pesquisas têm demonstrado que existem diferenças significativas entre países (GRAY; KOUHY \& LAVERS, 1995a), busca-se examinar quais são as características do disclosure ambiental de empresas brasileiras.

\section{METODOLOGIA}

O presente trabalho pode ser classificado com uma pesquisa teórico-empírica de caráter exploratório, na medida em que se busca examinar o disclosure voluntário de informações ambientais pelas empresas brasileiras. A descrição da metodologia está 
dividida em quatro partes: seleção da amostra, coleta dos dados, elaboração da estrutura conceitual e restrições do estudo.

\subsection{Seleção da Amostra}

A amostra do estudo consistiu das empresas abertas com ações listadas na BOVESPA, que publicaram Demonstrações Contábeis referentes a 2006, pertencentes a setores de alto impacto ambiental. Para a definição dos setores, utilizou-se como base a Lei $\mathrm{n}^{\circ}$. 10.165/2000, que classifica as atividades econômicas em baixo, médio e alto impacto ambiental. Para este estudo, foram selecionadas apenas as empresas cujas atividades apresentavam alto risco ambiental. 


\begin{tabular}{|c|c|}
\hline Segmento de Atuação & Empresa \\
\hline \multirow{4}{*}{ Artefatos de Cobre } & Caraíba Metais \\
\hline & Eluma Indústria e Comércio \\
\hline & Paranapanema \\
\hline & Sam Indústria \\
\hline \multirow{10}{*}{ Artefatos de Ferro e Aço } & Siderúrgica J.L. Aliperti \\
\hline & Confab Industrial \\
\hline & Fibam Companhia Industrial \\
\hline & Mangels Industrial \\
\hline & Metalúrgica Duque \\
\hline & Indústrias Micheletto \\
\hline & Panatlântica \\
\hline & Tekno Indústria e Comércio \\
\hline & Wetzel \\
\hline & Wiest \\
\hline Couro & Arthur Lange Indústria e Comércio \\
\hline \multirow{6}{*}{$\begin{array}{c}\text { Exploração, Refino e/ou Distribuição de } \\
\text { Combustíveis }\end{array}$} & Distribuidora de Petróleo Ipiranga \\
\hline & CIA Brasileira de Petróleo Ipiranga \\
\hline & Brasil Ecodiesel \\
\hline & Refinaria de Petróleo Ipiranga \\
\hline & Refinaria de Petróleo Manguinhos \\
\hline & Petróleo Brasileiro-Petrobras \\
\hline \multirow{3}{*}{ Fertilizantes e Defensivos } & Fertilizantes Heringer \\
\hline & Fertilizantes Fosfatados Fosfertil \\
\hline & Yara Brasil Fertilizantes \\
\hline \multirow{2}{*}{ Medicamentos e Outros Produtos } & Biomm \\
\hline & Cremer \\
\hline \multirow{5}{*}{ Minerais Metálicos } & Centenial Amapá \\
\hline & Centenial Rio \\
\hline & MMX Mineração e Metálicos \\
\hline & OGX Petróleo e Gás participações \\
\hline & CIA Vale do Rio Doce \\
\hline \multirow{7}{*}{ Papel e Celulose } & Aracruz Celulose \\
\hline & Celulose Irani \\
\hline & Klabin \\
\hline & CIA Melhoramentos São Paulo \\
\hline & Melpaper \\
\hline & Suzano Papel e Celulose \\
\hline & Votorantin Celulose e Papel \\
\hline \multirow{9}{*}{ Petroquímicos } & Braskem \\
\hline & Elekeiroz \\
\hline & GPC Participações \\
\hline & M G Poliester \\
\hline & Petroflex Indústria e Comércio \\
\hline & Petroquímica União \\
\hline & Pronor Petroquímica \\
\hline & Suzano Petroquímica \\
\hline & Unipar Petroquímica \\
\hline Produtos de Limpeza & Bombril \\
\hline Produtos de Uso Pessoal & Natura Cosméticos \\
\hline Químicos Diversos & Millennium Inorganic Chemicals \\
\hline \multirow{8}{*}{ Siderurgia } & Acesita Inox Brasil \\
\hline & Aços Villares \\
\hline & CIA Ferros e Ligas da Bahia Ferbasa \\
\hline & Gerdau \\
\hline & Gerdau Metalúrgica \\
\hline & CIA Siderúrgica Nacional \\
\hline & $\begin{array}{l}\text { Usina Siderúrgica de Minas Gerais } \\
\text { Usiminas }\end{array}$ \\
\hline & Vicunha Siderurgia \\
\hline
\end{tabular}

Quadro 2 - Empresas selecionadas 


\subsection{Coleta dos Dados}

Para analisar a evidenciação de informações ambientais das empresas, optou-se pela técnica de análise de conteúdo. O objetivo desta técnica é estudar de maneira rigorosa e sistemática a natureza das mensagens (KRIPPENDORFF, 1990), sendo que pode ser aplicada em conteúdos extremamente diversificados (BARDIN, 1977). Além disso, a análise de conteúdo permite a codificação de informações qualitativas em categorias (ABBOTT \& MONSEN, 1979) facilitando o processo de inferência acerca dos conhecimentos relativos às condições de produção/recepção (variáveis inferidas) das mensagens (BARDIN, 1977).

Um estágio extremamente importante na realização de estudos utilizando a análise de conteúdo é a decisão de qual documento analisar (KRIPPENDORFF, 1990). O presente trabalho optou por analisar as Demonstrações Financeiras Padronizadas (DFPs), que compreendem o Relatório da Administração, as Demonstrações Contábeis, as Notas Explicativas e parecer dos auditores independentes. Ressalta-se que algumas empresas possuem relatórios ambientais e sociais específicos como, por exemplo, o Relatório de Sustentabilidade. Outras divulgam informações acerca de suas práticas ambientais nos respectivos websites. Neste sentido, é mister salientar que a DFP não é o único canal de comunicação de informações ambientais. Entretanto, a justificativa pela escolha da DFP baseia-se em duas premissas fundamentais para realização de uma pesquisa: relevância e comparabilidade.

A relevância resulta da importância das Demonstrações Financeiras no processo de comunicação entre a empresa e seus stakeholders e, também, na formação de contratos: remuneração de executivos, distribuição de dividendos e juros sobre o capital próprio, pagamento de imposto ao governo, estabelecimento de restrições (covenants) de empréstimos etc. Do mesmo modo, as Demonstrações Financeiras também representam provavelmente o documento mais importante em termos de construção da imagem social da organização (NEIMARK, 1992).

Já a comparabilidade decorre do fato de que todas as empresas são obrigadas a enviar as DFPs à Comissão de Valores Mobiliários (CVM), enquanto que apenas algumas empresas divulgam relatórios específicos. 0 acesso às Demonstrações Contábeis foi por meio da internet, com a consulta nos sites das empresas. Algumas empresas não apresentavam suas DFPs referentes ao ano findo em 2006 em seus sites. Nesses casos, as DFPs foram retiradas do site da BOVESPA.

\subsection{Estrutura Conceitual}

Para codificar as informações de caráter ambiental, optou-se pela utilização do número de sentenças como unidade de registro. A classificação dos dados foi realizada por meio da elaboração de um arcabouço teórico dividido em oito categorias: políticas ambientais; sistema de gestão e auditoria ambiental; impacto de produtos e processos no meio ambiente; energia; informações financeiras ambientais; educação, pesquisa e treinamento; mercado de créditos de carbono; e outras informações ambientais. Esse arcabouço teórico foi elaborado a partir dos trabalhos de Gray, Kouhy e Lavers (1995b), Hackston e Milne (1996), Nossa (2002), Lima (2007) e Yusoff, Lehman e Nasir (2006). O Quadro 3 demonstra a estrutura conceitual elaborada, juntamente com os exemplos de informações ambientais evidenciadas pelas empresas da amostra. 


\begin{tabular}{|c|c|}
\hline Categorias Ambientais & Exemplo de Evidenciação Ambiental (DFP-2006) \\
\hline 1. Políticas Ambientais & \multirow[b]{2}{*}{$\begin{array}{l}\text { As ações de responsabilidade ambiental em } 2006 \\
\text { estiveram associadas principalmente à gestão de } \\
\text { emissões atmosféricas, recursos hídricos, } \\
\text { efluentes líquidos e resíduos; à avaliação e } \\
\text { monitoramento de ecossistemas; à remediação de } \\
\text { áreas impactadas e à garantia da conformidade } \\
\text { das instalações e operações às exigências legais } \\
\text { (PETROBRAS). }\end{array}$} \\
\hline $\begin{array}{l}\text { Declaração das políticas, } \\
\text { atuais e futuras; estabele } \\
\text { obediência normas e leis; } \\
\text { participações em índices } \\
\text { (sustentabilidade). }\end{array}$ & \\
\hline 2. $\mathrm{Si}$ & \multirow{2}{*}{$\begin{array}{l}\text { As usinas de Ipatinga e Cubatão, assim como } \\
\text { outras empresas do Grupo, possuem os seus } \\
\text { Sistemas de Gestão Ambiental certificados em } \\
\text { conformidade com a Norma ISO 14001:2004 } \\
\text { (USIMINAS). }\end{array}$} \\
\hline $\begin{array}{l}\text { Certificaç } \\
14.000, E \\
\text { descrição }\end{array}$ & \\
\hline 3. Im & \multirow[b]{2}{*}{$\begin{array}{l}\text { A participação de refis sobre os itens faturados } \\
\text { subiu de } 17,4 \% \text { para } 19,8 \% \text {, o que significa uma } \\
\text { relevante redução do impacto ambiental de nossos } \\
\text { produtos, tendo em vista que a média da massa de } \\
\text { uma embalagem de refil é } 54 \% \text { menor que a de } \\
\text { uma embalagem de produto regular (NATURA). }\end{array}$} \\
\hline $\begin{array}{l}\text { Despe } \\
\text { acond } \\
\text { desen } \\
\text { impac } \\
\text { reutili } \\
\text { derran }\end{array}$ & \\
\hline 4. En & \multirow[b]{2}{*}{$\begin{array}{l}\text { A Central de Co-Geração Termoelétrica, instalada } \\
\text { na Usina Presidente Vargas, em Volta Redonda, } \\
\text { com capacidade para gerar } 238 \mathrm{MW} \text {, usa como } \\
\text { combustível os próprios gases residuais da } \\
\text { produção siderúrgica (CSN) }\end{array}$} \\
\hline $\begin{array}{l}\text { Conse } \\
\text { nas op } \\
\text { despe } \\
\text { energ } \\
\text { energ }\end{array}$ & \\
\hline 5. Infc & \multirow{2}{*}{$\begin{array}{l}\text { Em } 2006 \text { os investimentos em proteção ao meio } \\
\text { ambiente totalizaram R\$ } 317 \text { milhões, mais que o } \\
\text { dobro do montante gasto em 2005, R\$ } 129 \text { milhões } \\
\text { (VALE DO RIO DOCE). }\end{array}$} \\
\hline $\begin{array}{l}\text { Invest } \\
\text { provis } \\
\text { conták }\end{array}$ & \\
\hline 6. Edu & \multirow{2}{*}{$\begin{array}{l}\text { No Endomarketing, na conscientização e } \\
\text { preparação dos funcionários para a inserção no } \\
\text { novo mercado através do fortalecimento do } \\
\text { relacionamento entre os colaboradores e, } \\
\text { "educando-os" quanto ao "combustível verde" } \\
\text { (REF. PETRO. MANGUINHOS). }\end{array}$} \\
\hline $\begin{array}{l}\text { Educa } \\
\text { (inter }\end{array}$ & \\
\hline 7. Me & \multirow{2}{*}{$\begin{array}{l}\text { Com a finalidade de criar valor e promover a } \\
\text { sustentabilidade de seus negócios, a Braskem tem } \\
\text { focado na identificação de oportunidades para } \\
\text { projetos de Mecanismo de Desenvolvimento Limpo } \\
\text { (BRASKEM). }\end{array}$} \\
\hline $\begin{array}{l}\text { Projet } \\
\text { limpo } \\
\text { de gas } \\
\text { de em }\end{array}$ & \\
\hline 00 & \multirow{2}{*}{$\begin{array}{l}\text { A Gerdau busca constantemente a excelência nos } \\
\text { negócios e na relação com o meio ambiente e a } \\
\text { sociedade, visando satisfazer as necessidades dos } \\
\text { clientes e criar valor para os acionistas, } \\
\text { comprometida com a realização das pessoas e com } \\
\text { o desenvolvimento sustentado da sociedade } \\
\text { (GERDAU). }\end{array}$} \\
\hline $\begin{array}{l}\text { gere } \\
\text { biodi } \\
\text { stake }\end{array}$ & \\
\hline
\end{tabular}

\section{Quadro 3 - Estrutura conceitual para levantamento das informações ambientais}

Uma vez definida a estrutura conceitual, o próximo passo constituiu na definição dos critérios para análise do tipo de informação ambiental evidenciada. Gray, Kouhy e Lavers (1995a) dividem a análise das informações em dois grandes grupos: evidência (evidence) e notícia (news). 
Pesquisas anteriores (HACKSTON \& MILNE, 1996; SALOMONE \& GALUCCIO, 2001; NOSSA, 2002; GRAY; KOUHY \& LAVERS, 1995a) dividem o tipo de evidência acerca da informação ambiental em quatro categorias:

- Declarativa: informação qualitativa expressa em termos descritivos;

* Quantitativa não-monetária: informação quantitativa expressa em números de natureza não-financeira;

- quantitativa monetária: informação quantitativa expressa em números de natureza financeira; e

- quantitativa monetária e não-monetária: informação quantitativa expressa em números de natureza financeira e não-financeira.

Já em relação ao tipo de notícia, Gray, Kouhy e Lavers (1995a) recomendam a utilização de três categorias:

- Informação boa: declarações que reflitam crédito para a companhia;

- informação ruim: declarações que reflitam descrédito para a companhia; e

* informação neutra: declarações cujo crédito/descrédito para a companhia não é obvio.

Finalmente, uma questão relevante acerca da análise das informações de caráter ambiental diz respeito à localização da informação. Basicamente, as Demonstrações Financeiras podem ser divididas em quatro grandes partes: Relatório da Administração, Demonstrações Contábeis propriamente ditas, Notas Explicativas e Parecer do auditor. A localização da informação é importante na medida em que possibilita algumas inferências do tipo: informações evidenciadas no Relatório da Administração não são auditadas ou informações contidas nos balanços servem para a formação de covenants.

\subsection{Restrições e Limitações da Pesquisa}

Primeiramente, faz-se necessário ressaltar que a evidenciação voluntária de informações ambientais pode não ser uma avaliação representativa da performance ambiental da empresa (HUGHES; ANDERSON \& GOLDEN, 2001). Nessa ótica, o presente trabalho não pretende estabelecer essa relação. Afinal, muitas empresas poderiam possuir uma postura ambiental correta e não divulgar nenhuma informação. Por outro lado, outras empresas poderiam adotar uma postura inadequada perante o meio ambiente e divulgar apenas informações boas já que não são obrigadas a realizar essa divulgação.

Quanto à amostra, esta envolveu apenas empresas listadas na BOVESPA e pertencentes a setores de alto impacto ambiental. Logo, os resultados não devem ser generalizados para outras empresas. Do mesmo modo, foram analisadas somente as Demonstrações Financeiras Padronizadas (DFPs). Assim, outras pesquisas que analisarem outros documentos (Relatório de Sustentabilidade, Relatórios Anuais, Relatório 20-F etc.) podem identificar uma quantidade diferenciada de informações ambientais. Igualmente, analisou-se apenas o exercício findo em 2006. Neste sentido, sugere-se que futuros trabalhos realizem uma análise temporal a fim de expandir esta pesquisa.

A técnica utilizada para coletar os dados também possui algumas limitações. Segundo Bardin (1977) a análise de conteúdo opera entre dois pólos: rigor da objetividade e fertilidade da subjetividade. Buscando reduzir essa subjetividade, dois codificadores independentes realizaram a coleta, classificação e análise das informações ambientais 
evidenciadas pelas empresas. Posteriormente, as informações que despertaram dúvidas foram analisadas conjuntamente a fim de padronizar as análises.

\section{RESULTADOS}

Os resultados da pesquisa estão divididos em duas partes: análise setorial e análise das oito categorias que compõem a estrutura conceitual. Nota-se que as 58 empresas que compõem a amostra do estudo evidenciaram um total de 607 sentenças relacionadas ao meio ambiente. A Tabela 1 apresenta a evidenciação das categorias ambientais por setores, dispostos em seis classificações.

Tabela 1 - Evidenciação das categorias ambientais por setores

\begin{tabular}{|l|c|c|c|c|c|c|c|}
\hline CATEGORIAS AMBIENTAIS & A & B & C & D & E & F & TOTAL \\
\hline 1 Políticas Ambientais & 9 & 45 & 19 & 44 & 23 & 6 & $\mathbf{1 4 6}$ \\
\hline $\begin{array}{l}\text { 2 Sistemas de Gerenciamento } \\
\text { Ambiental }\end{array}$ & 3 & 21 & 8 & 13 & 5 & 1 & $\mathbf{5 1}$ \\
\hline $\begin{array}{l}\text { 3 Impactos dos Produtos e } \\
\text { Processos }\end{array}$ & 4 & 38 & 5 & 19 & 10 & 15 & $\mathbf{9 1}$ \\
\hline 4 Energia & 0 & 10 & 2 & 9 & 6 & 3 & 30 \\
\hline $\begin{array}{l}\text { 5 Informações Financeiras } \\
\text { Ambientais }\end{array}$ & 4 & 39 & 23 & 35 & 11 & 4 & 116 \\
\hline $\begin{array}{l}\text { 6 Educação, Pesquisa e } \\
\text { Treinamento }\end{array}$ & 1 & 13 & 5 & 7 & 13 & 6 & 45 \\
\hline $\begin{array}{l}\text { 7 Mercado de Créditos de } \\
\text { Carbono }\end{array}$ & 6 & 10 & 9 & 14 & 18 & 5 & 62 \\
\hline 8 Outras Informações Ambientais & 4 & 21 & 11 & 11 & 15 & 4 & 66 \\
\hline MÉDIA POR EMPRESA & $\mathbf{2}$ & $\mathbf{1 5}$ & $\mathbf{8}$ & $\mathbf{2 5}$ & $\mathbf{1 4}$ & $\mathbf{6}$ & $\mathbf{1 0}$ \\
\hline TOTAL & $\mathbf{3 1}$ & $\mathbf{1 9 7}$ & $\mathbf{8 2}$ & $\mathbf{1 5 2}$ & $\mathbf{1 0 1}$ & $\mathbf{4 4}$ & $\mathbf{6 0 7}$ \\
\hline
\end{tabular}

Legenda dos Setores:

A - Artefatos de Cobre, Ferro e Aço

B - Siderurgia e Minerais Metálicos

C - Petroquímicos e Químicos Diversos

D - Exploração, Refino e/ou Distribuição de Combustíveis

E - Papel e Celulose

F - Fertilizantes e Defensivos, Medicamentos, Couro, Produtos de Limpeza e Uso Pessoal

Nota-se que a categoria "Políticas Ambientais" foi a predominante com 146 sentenças. Na seqüência, aparece a categoria "Informações Financeiras Ambientais" com o total de 116 sentenças, sendo que destas 58 dizem respeito aos investimentos ambientais.

Constata-se que o setor que evidenciou o maior número de categorias ambientais foi o de "Siderurgia e Minerais Metálicos" com 197 sentenças. No entanto, ressalta-se que na média de evidenciação por empresa o setor de destaque foi o de "Exploração, Refino e/ou Distribuição de Combustíveis".

A empresa com maior volume de divulgação é a Petrobras, que evidenciou 95 sentenças relacionadas ao meio ambiente em suas Demonstrações Financeiras no exercício findo em 2006. 
Por outro lado, o setor de "Artefatos de Cobre, Ferro e Aço" divulgou em média duas sentenças por empresa. Do mesmo modo, os setores de "Fertilizantes e Defensivos, Medicamentos, Couro, Produtos de Limpeza e Uso Pessoal" evidenciaram em seus relatórios 44 sentenças referentes ao meio ambiente. Destas, 30 sentenças foram divulgadas por uma única empresa, a Natura Cosméticos.

Das 58 empresas potencialmente poluidoras, 17 não evidenciaram informações ambientais. São elas: Eluma Indústria e Comércio, Sam Indústria, Siderúrgica J.L. Aliperti, Fibam Companhia Industrial, Metalúrgica Duque, Indústrias Micheletto, Panatlântica, Tekno, Wiest, Centenial Amapá, Centenial Rio, OGX, Elekeiroz, Fertilizantes Heringer, Yara Brasil Fertilizantes, Biomm e Arthur Lange Indústria e Comércio.

No que se refere à média de disclosure, quando analisada a totalidade da amostra tem-se o resultado de 10 sentenças por empresa. Se desconsideradas as entidades que não evidenciaram informações ambientais na DFP tem-se uma média de 15 sentenças por companhia.

As tabelas a seguir apresentam as análises realizadas a partir das oito categorias (políticas ambientais; sistemas de gerenciamento ambiental; impactos dos produtos e processos; energia; informações financeiras ambientais; educação, pesquisa e treinamento; mercado de créditos de carbono; e outras informações ambientais), bem como a análise do tipo de evidência (declarativa; monetária; não-monetária; e monetária e não-monetária) e a característica da notícia (boa, ruim ou neutra).

Tabela 2 - Evidenciação das políticas ambientais

\begin{tabular}{|c|c|c|c|c|c|c|c|}
\hline \multirow[b]{2}{*}{ Categoria e Subcategorias Ambientais } & \multicolumn{4}{|c|}{ Evidência } & \multicolumn{3}{|c|}{ Notícia } \\
\hline & Declar & Mon & Não-Mon & Mon/Não Mon & Boa & Ruim & Neutra \\
\hline 1 Políticas Ambientais & 125 & 3 & 16 & 2 & 146 & 0 & 0 \\
\hline $\begin{array}{l}1.1 \text { Declaração das políticas/práticas } \\
\text { atuais e futuras }\end{array}$ & 68 & 0 & 2 & 0 & 70 & 0 & 0 \\
\hline $\begin{array}{l}1.2 \text { Estabelecimento de metas e } \\
\text { objetivos ambientais }\end{array}$ & 7 & 3 & 6 & 2 & 18 & 0 & 0 \\
\hline $\begin{array}{l}1.3 \text { Declarações de que a empresa está } \\
\text { em obediência com as leis, licenças e } \\
\text { órgãos ambientais }\end{array}$ & 25 & 0 & 3 & 0 & 28 & 0 & 0 \\
\hline 1.4 Parcerias ambientais & 3 & 0 & 1 & 0 & 4 & 0 & 0 \\
\hline $\begin{array}{l}\text { 1.5 Prêmios e participações em índices } \\
\text { ambientais }\end{array}$ & 22 & 0 & 4 & 0 & 26 & 0 & 0 \\
\hline
\end{tabular}

Percebe-se que todas as sentenças acerca das "Políticas Ambientais" das empresas são notícias boas. Além disso, verifica-se que das 146 sentenças, 125 são do tipo declarativa, ou seja, sem nenhuma quantificação. Entre as subcategorias enfatizam-se as declarações das políticas e práticas atuais e futuras das empresas que perfazem um total de 70 sentenças.

A Gerdau, por exemplo, afirmava que "a Política de Meio Ambiente tem como objetivo estabelecer condutas que assegurem a conservação ambiental e contribuam para o desenvolvimento sustentado da sociedade". Já a Celulose Irani mencionava que "atua com total respeito ao meio ambiente, monitorando ações e interações resultantes da sua operação, com o objetivo de prevenir riscos e otimizar os recursos existentes".

Quanto à localização das informações acerca das políticas ambientais das empresas nas Demonstrações Financeiras Padronizadas (DFPs), verificou-se que a maioria delas 
encontra-se no Relatório da Administração (121 sentenças) e o restante aparece nas Notas Explicativas ( 25 sentenças).

Tabela 3 - Evidenciação dos sistemas de gerenciamento ambiental

\begin{tabular}{|l|c|c|c|c|c|c|c|}
\hline & \multicolumn{4}{|c|}{ Evidência } & \multicolumn{3}{c|}{ Notícia } \\
\cline { 2 - 9 } Categoria e Subcategorias Ambientais & Declar & Mon & Não-Mon & Mon/Não Mon & Boa & Ruim & Neutra \\
\hline 2 Sistemas de Gerenciamento & $\mathbf{4 4}$ & $\mathbf{0}$ & $\mathbf{7}$ & $\mathbf{0}$ & $\mathbf{5 1}$ & $\mathbf{0}$ & $\mathbf{0}$ \\
\hline 2.1 ISOs 9000 e/ou 14.000 & 22 & 0 & 7 & 0 & 29 & 0 & 0 \\
\hline 2.2 Auditoria Ambiental & 6 & 0 & 0 & 0 & 6 & 0 & 0 \\
\hline 2.3 Gestão ambiental & 16 & 0 & 0 & 0 & 16 & 0 & 0 \\
\hline
\end{tabular}

Das 51 sentenças relacionadas à categoria "Sistemas de Gerenciamento Ambiental", 44 são declarativas e sete classificam-se como não-monetárias. Verifica-se, ainda, que a totalidade das notícias tem caráter positivo à entidade, e que a maioria das informações encontra-se disponível no Relatório da Administração (47 sentenças).

A subcategoria com a maior quantidade de sentenças refere-se às normas ISOs 9.000 e/ou 14.000. Um exemplo dessa subcategoria é o da empresa Natura Cosméticos, que divulgou a continuidade das certificações ISO 9001 e ISO 14001.

Em contrapartida, a subcategoria auditoria ambiental foi encontrada em seis menções. Um exemplo de sentença de auditoria ambiental é a da GPC Participações, conforme segue: "os resultados das auditorias ambientais atestaram a conformidade de nossos processos de controle em relação à legislação ambiental vigente, sem nenhuma constatação de não-conformidade significativa”.

Tabela 4 - Evidenciação dos impactos dos produtos e processos no meio ambiente

\begin{tabular}{|l|c|c|c|c|c|c|c|}
\hline \multirow{2}{*}{ Categoria e Subcategorias Ambientais } & \multicolumn{4}{|c|}{ Evidência } & \multicolumn{3}{c|}{ Notícia } \\
\cline { 2 - 9 } & Declar & Mon & Não-Mon & Mon/Não Mon & Boa & Ruim & Neutra \\
\hline 3 Impactos dos Produtos e Processos & 46 & 0 & 45 & 0 & 77 & 10 & 4 \\
\hline 3.1 Desperdícios / Resíduos & 3 & 0 & 4 & 0 & 1 & 5 & 1 \\
\hline $\begin{array}{l}\text { 3.2 Processo de Acondicionamento } \\
\text { (Embalagem) }\end{array}$ & 1 & 0 & 3 & 0 & 4 & 0 & 0 \\
\hline 3.3 Reciclagem & 13 & 0 & 14 & 0 & 27 & 0 & 0 \\
\hline $\begin{array}{l}\text { 3.4 Desenvolvimento de Produtos } \\
\text { Ecológicos }\end{array}$ & 7 & 0 & 0 & 0 & 7 & 0 & 0 \\
\hline 3.5 Impacto na Área de Terra Utilizada & 1 & 0 & 0 & 0 & 1 & 0 & 0 \\
\hline 3.6 Uso Eficiente / Reutilização da Água & 14 & 0 & 13 & 0 & 24 & 1 & 2 \\
\hline 3.7 Vazamentos / Derramamentos & 0 & 0 & 3 & 0 & 0 & 3 & 0 \\
\hline 3.8 Reparos aos danos ambientais & 7 & 0 & 8 & 0 & 13 & 1 & 1 \\
\hline
\end{tabular}

Nota-se que a maioria das sentenças de "Impactos dos Produtos e Processos no Meio Ambiente" diz respeito à reciclagem e ao uso eficiente ou reutilização da água. Algumas empresas, como Gerdau Metalúrgica, por exemplo, afirmaram que "reciclam parte dos resíduos gerados pela empresa, o que auxilia na redução do impacto ambiental". Outro ponto enfatizado pelas empresas é o reaproveitamento das águas no processo produtivo, como é o caso da Acesita Inox Brasil que conseguiu reaproveitar $96 \%$ da água utilizada no período de 2006. 
Verifica-se também que $11 \%$ das sentenças sobre "Impactos dos Produtos e Processos" fazem menção a notícias ruins. Esse fato pode ser explicado por duas subcategorias, desperdícios/resíduos e vazamentos/derramamentos, que perfazem 0 montante de oito, do total das 10 notícias ruins.

As informações sobre os "Impactos dos Produtos e Processos no Meio Ambiente" aparecem mais acentuadamente no Relatório da Administração (75 sentenças) e, em alguns casos, nas Notas Explicativas (16 sentenças).

Tabela 5 - Evidenciação acerca das políticas de energia

\begin{tabular}{|l|c|c|c|c|c|c|c|}
\hline \multirow{2}{*}{ Categoria e Subcategorias Ambientais } & \multicolumn{4}{|c|}{ Evidência } & \multicolumn{3}{c|}{ Notícia } \\
\cline { 2 - 9 } & Declar & Mon & Não-Mon & Mon/Não Mon & Boa & Ruim & Neutra \\
\hline 4 Energia & $\mathbf{2 0}$ & $\mathbf{0}$ & $\mathbf{1 0}$ & $\mathbf{0}$ & $\mathbf{2 9}$ & $\mathbf{1}$ & 0 \\
\hline $\begin{array}{l}\text { 4.1 Conservação e/ou utilização mais } \\
\text { eficiente de energia nas operações }\end{array}$ & 2 & 0 & 9 & 0 & 10 & 1 & 0 \\
\hline $\begin{array}{l}\text { 4.2 Utilização de materiais } \\
\text { desperdiçados na produção de energia }\end{array}$ & 1 & 0 & 0 & 0 & 1 & 0 & 0 \\
\hline $\begin{array}{l}\text { 4.3 Discussão sobre a preocupação com a } \\
\text { possível falta de energia }\end{array}$ & 1 & 0 & 0 & 0 & 1 & 0 & 0 \\
\hline $\begin{array}{l}\text { 4.4 Desenvolvimento de novas fontes de } \\
\text { energia }\end{array}$ & 16 & 0 & 1 & 0 & 17 & 0 & 0 \\
\hline
\end{tabular}

Das 58 empresas pesquisadas somente 13 divulgaram informações referentes à categoria "Energia", sendo essas empresas pertencentes aos setores de Siderurgia, Minerais Metálicos, Petroquímico, Papel e Celulose, Uso Pessoal e Exploração, Refino e/ou Distribuição de Combustíveis. As subcategorias predominantes foram as de desenvolvimento/exploração de novas fontes de energia (17 sentenças) e de conservação e/ou utilização mais eficiente nas operações (11 sentenças).

No que se refere ao tipo de evidenciação, as informações foram classificadas em declarativas (20 sentenças) e não-monetárias (10 sentenças). Já em relação às características das menções, estas se configuram como notícias boas e, aparecem, sobretudo, no Relatório da Administração.

Com relação às "Informações Financeiras Ambientais", 50\% refere-se a investimentos ambientais. É importante afirmar que essa categoria foi a única que apresentou maior número de sentenças do tipo monetária. Isso se deve principalmente às subcategorias investimentos em meio ambiente e passivos ambientais. A Tabela 6 mostra os resultados dessa categoria. 
Tabela 6 - Evidenciação das informações financeiras ambientais

\begin{tabular}{|l|c|c|c|c|c|c|c|}
\hline & \multicolumn{5}{|c|}{ Evidência } & \multicolumn{3}{c|}{ Notícia } \\
\cline { 2 - 10 } Categoria e Subcategorias Ambientais & Declar & Mon & Não-Mon & Mon/Não Mon & Boa & Ruim & Neutra \\
\hline 5 Informações Financeiras Ambientais & $\mathbf{4 1}$ & $\mathbf{6 5}$ & $\mathbf{3}$ & $\mathbf{7}$ & $\mathbf{7 6}$ & $\mathbf{1 3}$ & $\mathbf{2 7}$ \\
\hline 5.1 Investimentos Ambientais & 12 & 39 & 1 & 6 & 57 & 0 & 1 \\
\hline 5.2 Custos/Despesas Ambientais & 5 & 5 & 0 & 0 & 4 & 1 & 5 \\
\hline 5.3 Passivos/Provisões Ambientais & 7 & 16 & 1 & 1 & 4 & 11 & 10 \\
\hline 5.4 Práticas Contábeis de Itens & & & & & & & \\
Ambientais & 13 & 0 & 0 & 0 & 6 & 0 & 7 \\
\hline 5.5 Seguro Ambiental & 4 & 1 & 1 & 0 & 4 & 1 & 1 \\
\hline $\begin{array}{l}\text { 5.6 Ativos Ambientais tangíveis e } \\
\text { intangíveis }\end{array}$ & 0 & 4 & 0 & 0 & 1 & 0 & 3 \\
\hline
\end{tabular}

Com relação aos investimentos ambientais, a Petrobras, por exemplo, mencionou que "o Programa Petrobras Ambiental recebeu 856 inscrições e incorporou a seus patrocínios 36 novos projetos, que totalizaram investimentos de R\$ 48 milhões". Outro relato é o da Companhia Vale do Rio Doce que "em 2006 os investimentos em proteção ao meio ambiente totalizaram R\$317 milhões, mais que o dobro do montante gasto em 2005, R\$ 129 milhões".

Salienta-se que aproximadamente $11 \%$ e $23 \%$ das "Informações Financeiras Ambientais" fazem menção a, respectivamente, notícias ruins e neutras. Esse fato pode ser explicado pela incidência de sentenças sobre passivos ambientais. Normalmente, as informações sobre passivos ambientais referem-se a aspectos negativos, como no seguinte caso da Refinaria de Petróleo Manguinhos: "vazamento de óleo na Baía de Guanabara ocorrido em novembro de 2001, a Sociedade manteve registrado em 31 de dezembro de 2006 e de 2005 o montante de R\$ 1.000 referente ao auto de infração da ANP (Agência Nacional do Petróleo)". Vale enfatizar que quase a totalidade (96\%) dos passivos ambientais foi demonstrada nas Notas Explicativas das empresas.

Tabela 7 - Evidenciação da categoria educação, pesquisa e treinamento ambiental

\begin{tabular}{|l|c|c|c|c|c|c|c|}
\hline \multirow{2}{*}{ Categoria e Subcategorias Ambientais } & \multicolumn{4}{|c|}{ Evidência } & \multicolumn{3}{c}{ Notícia } \\
\cline { 2 - 9 } & Declar & Mon & Não-Mon & Mon/Não Mon & Boa & Ruim & Neutra \\
\hline 6 Educação, Pesquisa e Treinamento & 31 & 3 & 9 & 2 & 44 & 0 & 1 \\
\hline $\begin{array}{l}\text { 6.1 Educação Ambiental } \\
\text { (internamente e/ou comunidade) }\end{array}$ & 24 & 3 & 5 & 2 & 34 & 0 & 0 \\
\hline $\begin{array}{l}\text { 6.2 Pesquisas relacionadas ao meio } \\
\text { ambiente }\end{array}$ & 7 & 0 & 4 & 0 & 10 & 0 & 1 \\
\hline
\end{tabular}

Conforme a Tabela 7, as sentenças pertencem especialmente à subcategoria educação ambiental. Diversas empresas relatam que possuem projetos na área de educação ambiental, como é o caso da Suzano Papel e Celulose, que desenvolve um projeto em escolas da rede pública, com o objetivo de estimular a consciência e as práticas de preservação ambiental dos alunos e de suas comunidades. Do mesmo modo, a Millennium Inorganic Chemicals destaca, entre os projetos realizados em 2006, "o Programa de Educação Ambiental realizado no Centro de Preservação de Animais Silvestres e da Flora Local da mina da Paraíba, onde alunos e professores recebem informações sobre preservação do meio ambiente". 
Além disso, é relevante informar que as sentenças são, em sua maioria, divulgadas no Relatório da Administração (39 sentenças), referem-se a notícias boas e são apresentadas de forma declarativa.

Tabela 8 - Evidenciação da categoria mercado de créditos de carbono

\begin{tabular}{|l|c|c|c|c|c|c|c|}
\hline \multirow{2}{*}{ Categoria e Subcategorias Ambientais } & \multicolumn{4}{|c|}{ Evidência } & \multicolumn{3}{c|}{ Notícia } \\
\cline { 2 - 9 } & Declar & Mon & Não-Mon & Mon/Não Mon & Boa & Ruim & Neutra \\
\hline 7 Mercado de Créditos de Carbono & $\mathbf{4 5}$ & $\mathbf{2}$ & $\mathbf{1 5}$ & $\mathbf{0}$ & $\mathbf{5 8}$ & $\mathbf{2}$ & $\mathbf{2}$ \\
\hline $\begin{array}{l}\text { 7.1 Projetos de Mecanismos de } \\
\text { Desenvolvimento Limpo (MDL) }\end{array}$ & 14 & 0 & 0 & 0 & 14 & 0 & 0 \\
\hline 7.2 Créditos de Carbono & 5 & 0 & 2 & 0 & 7 & 0 & 0 \\
\hline $\begin{array}{l}\text { 7.3 Emissão de Gases do Efeito Estufa } \\
\text { (GEE) }\end{array}$ & 24 & 2 & 13 & 0 & 35 & 2 & 2 \\
\hline $\begin{array}{l}\text { 7.4 Certificados de Emissões Reduzidas } \\
\text { (CER) }\end{array}$ & 2 & 0 & 0 & 0 & 2 & 0 & 0 \\
\hline
\end{tabular}

Em relação às especificações do "Mercado de Créditos de Carbono", percebe-se, a partir da Tabela 8, que aproximadamente $63 \%$ das sentenças são relativas às emissões de Gases do Efeito Estufa (GEE), sendo a maior parte evidenciada pelos setores de Exploração, Refino e/ou Distribuição de Combustíveis e de Papel de Celulose. Como exemplo, a Petrobras cita que "monitora, por meio do Sistema de Gestão de Emissões Atmosféricas (SIGEA), os principais GEE (dióxido de carbono, metano e óxido nitroso) - que emite em suas atividades".

No que concerne aos certificados de emissões reduzidas, somente as empresas Gerdau e Gerdau Metalúrgica fazem referência a esses certificados nos relatórios. A menção feita por estas empresas está relacionada ao intangível consolidado referente, substancialmente, a Certificados de Redução de Emissão de Carbono.

De maneira geral, as informações sobre o 'Mercado de Créditos de Carbono' aparecem no Relatório da Administração e, em poucas situações, nas Notas Explicativas. Corroborando com as demais categorias analisadas no estudo, o disclosure da categoria 'Mercado de Créditos de Carbono' é caracterizado por notícias boas e pelo tipo de evidência declarativa.

Tabela 9 - Evidenciação de outras informações ambientais

\begin{tabular}{|l|c|c|c|c|c|c|c|}
\hline \multirow{2}{*}{ Categoria e Subcategorias Ambientais } & \multicolumn{3}{|c|}{ Evidência } & \multicolumn{2}{c|}{ Notícia } \\
\cline { 2 - 8 } & Declar & Mon & Não-Mon & Mon/Não Mon & Boa & Ruim & Neutra \\
\hline 8 Outras Informações Ambientais & 56 & 0 & 10 & 0 & 66 & 0 & 0 \\
\hline $\begin{array}{l}\text { 8.1 Qualquer menção sobre } \\
\text { Sustentabilidade }\end{array}$ & 24 & 0 & 0 & 0 & 24 & 0 & 0 \\
\hline 8.2 Gerenciamento de & & & & & & & \\
Florestas/Reflorestamentos & 14 & 0 & 8 & 0 & 22 & 0 & 0 \\
\hline 8.3 Conservação da biodiversidade & 1 & 0 & 1 & 0 & 2 & 0 & 0 \\
\hline 8.4 Stakeholders & 17 & 0 & 1 & 0 & 18 & 0 & 0
\end{tabular}

Acrescenta-se que do total das 66 sentenças sobre "Outras Informações Ambientais", 56 se localizam no Relatório da Administração e 10 nas Notas Explicativas. Além disso, a totalidade dessas informações são aspectos positivos da empresa em relação ao meio ambiente, ou seja, correspondem a notícias boas. Quanto ao tipo de evidência, 
existe a predominância de sentenças declarativas, apesar das quantitativas não-monetárias também se fazerem presentes.

Por fim, vale realçar que as subcategorias em destaque foram aquelas concernentes às menções sobre sustentabilidade $e$ sobre $o$ gerenciamento de florestas e reflorestamentos. Por outro lado, apenas a Petrobras divulgou aspectos sobre a conservação da biodiversidade, como a sentença a seguir: "o padrão contempla a caracterização de áreas protegidas ou ambientalmente sensíveis influenciadas pelas operações da Companhia, visando à proteção, mitigação de impactos à biodiversidade e recuperação desses locais".

\section{CONSIDERAÇÕES FINAIS}

O presente trabalho objetivou examinar as características do disclosure voluntário de informações ambientais de empresas brasileiras. A amostra deste estudo consiste nas empresas abertas com ações listadas na Bolsa de Valores de São Paulo (BOVESPA) e pertencentes a setores de alto impacto ambiental segundo a Lei $n^{\circ}$. 10.165/2000, que dispõe sobre a Política Nacional do Meio Ambiente.

A justificativa da pesquisa baseia-se em duas premissas essenciais para a realização de um trabalho científico: a crescente demanda da sociedade por maior accountability no que tange a relação das empresas com o meio ambiente e a escassez de literatura acerca do tema evidenciação ambiental no cenário brasileiro. As principais constatações do estudo são:

- As 58 empresas que compõem a amostra evidenciaram um total de 607 sentenças com informações acerca do meio ambiente, sendo que a categoria com maior volume de evidenciação foi a de "Políticas Ambientais" seguida pela de "Informações Financeiras Ambientais".

- O setor que evidenciou o maior número de categorias ambientais foi o de "Siderurgia e Minerais Metálicos" com 197 sentenças, seguido pelo setor de "Exploração, Refino e/ou Distribuição de Combustíveis".

* A empresa com maior volume de divulgação é a Petrobras, que evidenciou 95 sentenças relacionadas ao meio ambiente em suas Demonstrações Financeiras no exercício findo em 2006.

- Corroborando pesquisas anteriores, a maioria das informações ambientais é evidenciada no Relatório da Administração (78\%), de forma declarativa (67\%) e é apresentada por meio de notícias boas (90\%).

Os resultados deste estudo estão condizentes com a Teoria do Disclosure Voluntário (VERRECCHIA, 2001; DYE, 2001), uma vez que as empresas divulgaram poucas informações negativas a seu respeito de forma voluntária.

De certa forma, o presente estudo levanta questões acerca da credibilidade e da utilidade das informações ambientais evidenciadas nas Demonstrações Contábeis, uma vez que grande parte dessas informações é evidenciada no Relatório da Administração e não são auditadas.

Percebe-se que a maioria das informações com evidência "neutra" ou "ruim" é evidenciada em Notas Explicativas e diz respeito a passivos ambientais. Nestes casos, a empresa é muitas vezes "forçada" a evidenciar essas informações para não incorrer no problema de seleção adversa. 
0 trabalho também apresenta evidências que sugerem a necessidade de normatização da evidenciação ambiental. A elaboração de uma norma que obrigue as empresas a evidenciar suas interações com o meio ambiente traria maior accountability a estas entidades. Do mesmo modo, a auditoria dessas informações também seria necessária como uma forma de garantir sua fidedignidade. Finalmente, o estudo espera contribuir para a discussão de um tema extremamente importante para a prática empresarial e, todavia incipiente na literatura nacional.

\section{REFERÊNCIAS}

ABBOTT, Walter; MONSEN, Joseph. On the measurement of corporate social responsibility: self-reported disclosures as a method of measuring corporate social environment. Academy of Management Journal. v. 22, p. 501-515, 1979.

AL-KHATER, Khalid; NASER, Kamal. Users' perception of corporate social responsibility and accountability: evidence from an emerging economy. Managerial Auditing Journal. v. 18, p. 538-548, 2003.

BARDIN, Laurence. Análise de conteúdo. Lisboa: Edições 70, 1977.

BEAVER, William. Financial reporting: an accounting revolution. Prentice Hall, 1998.

BORBA, José Alonso; ROVER, Suliani; MURCIA, Fernando. Do Brazilian corporations disclose environmental information? Evidences from financial statement published in the New York Securities Exchange and in the Bolsa de Valores de São Paulo. In: Asian Pacific Conference, 2006, Maui. Anais... Asian Pacific, 2006. CD-ROM.

BRAMMER, Stephen; PAVELIN, Stephen. Voluntary environmental disclosures by large UK companies. Journal of Business Finance and Accounting. v. 33, p. 1168-1188, 2006.

COSTA, Rodrigo; MARION, José. A uniformidade na evidenciação das informações ambientais. Revista de Contabilidade \& Finanças. v. 43, p. 20-33, 2007.

COUPLAND, Christine. Corporate social and environmental responsibility in web-based reports: currency in the banking sector. Critical Perspectives on Accounting. v. 17, p. 865-881, 2006.

COWAN, Stacey; GADENNE, David. Australian corporate environmental reporting: a comparative analysis of disclosure practices across voluntary and mandatory disclosure systems. Journal of Accounting and Organizational Change. v. 1, p. 165-179, 2005.

CUNHA, Jacqueline; RIBEIRO, Maisa. Divulgação voluntária de informações de natureza social: um estudo nas empresas brasileiras. In: ENANPAD, 30, 2006, Salvador. Anais... Brasília: ANPAD, 2006. CD-ROM.

DEEGAN, Craig. The legitimizing effect of social and environmental disclosures: a theoretical foundation. Accounting, Auditing and Accountability Journal. v. 15, p. 282307, 2002.

DYE, Ronald. An evaluation of "essays on disclosure" and the disclosure literature in accounting. Journal of Accounting and Economics. v. 32, p. 181-235, 2001.

FERREIRA, Aracéli. Contabilidade de custos para a gestão do meio ambiente. Cadernos de Estudo da USP. 12, p.1-6, 1995.

GALLON, Alessandra Vasconcellos; SOUZA, Flávia Cruz; ROVER, Suliani; BELLEN, Hans Michael van. Produção científica e perspectivas teóricas da área ambiental: um 
levantamento a partir dos artigos publicados em congressos e periódicos nacionais da área de contabilidade e administração. In: Congresso USP de Contabilidade e Controladoria, 2006, São Paulo. Anais... São Paulo: USP, 2007. CD-ROM.

GRAY, Rob; JAVAD, Mohammed; POWER, David M.; SINCLAIR, C. Donald. Social and Environmental Disclosure and Corporate Characteristics: A Research Note and Extension. Journal of Business Finance and Accounting. v. 28, p. 327-356, 2001.

GRAY, Rob; OWEN, Dave; ADAMS, Carol. Accounting \& Accountability: changes and challenges in corporate social and environmental reporting. London: Prentice Hall, 1996.

GRAY, Rob; KOUHY, Reza; LAVERS, Simon. Corporate social and environmental reporting: a review of the literature and a longitudinal study of UK disclosure. Accounting, Auditing and Accountability Journal. v. 8, p. 47-77, 1995a.

- Methodological themes: constructing a research database of social and environmental reporting by UK companies. Accounting, Auditing and Accountability Journal. v. 8, p. 78-101, 1995b.

HACKSTON, David; MILNE, Markus. Some determinants of social and environmental disclosure in New Zealand companies. Accounting, Auditing and Accountability Journal. v. 9, p. 77-108, 1996.

HUGHES, Susan; ANDERSON, Allison; GOLDEN, Sarah. Corporate environmental disclosures: are they useful in determining environmental performance. Journal of Accounting and Public Policy. v. 20, p. 217-240, 2001.

IMAM, Shahed. Coporate social performance reporting in Bangladesh. Managerial Auditing Journal. v. 15, p. 133-141, 2000.

LABATT, Sonia; WHITE, Rodney. Environmental finance. New York: Wiley, 2002.

LIMA, Gerlando. Utilização da Teoria da Divulgação para avaliação da relação do nível de disclosure com o custo da dívida das empresas brasileira. 2007. 118f. Tese (Doutorado em Controladoria e Contabilidade) - Faculdade de Economia, Administração e Contabilidade, Universidade de São Paulo, São Paulo. 2007.

LOPES, Alexsandro; MARTINS, Eliseu. Teoria da contabilidade: uma nova abordagem. São Paulo: Atlas, 2005.

KRIPPENDORFF, Klaus. Metodología de análisis de contenido: teoría y práctica. Barcelona: Paidós Comunicación, 1990.

KUASIRIKUN, Nongnooch; SHERER, Michel. Corporate social accounting in Thailand. Accounting, Auditing and Accountability Journal. v. 17, p. 629-660, 2004.

NEIMARK, Marilyn. The hidden dimensions of annual reports. London: Chapman, 1992.

NEWSON, Mark; DEEGAN, Craig. Global expectations and their association with corporate social disclosures practices in Australia, Singapore and North Korea. The International Journal of Accounting. v. 37, p.183-213, 2002.

NOSSA, Valcemiro. Disclosure ambiental: uma análise do conteúdo dos relatórios ambientais de empresas do setor de papel e celulose em nível internacional. 2002. 246f. Tese (Doutorado em Controladoria e Contabilidade) - Faculdade de Economia, Administração e Contabilidade, Universidade de São Paulo, São Paulo. 2002.

O'DWYER, Bredan; OWEN, David. Assurance statement practice in environmental, social and sustainability reporting: a critical evaluation. The British Accounting Review. v. 37, p. 205-229, 2005. 
PINTO, Anacleto; RIBEIRO, Maisa. Balanço Social: a avaliação das informações fornecidas por empresas industriais situadas no estado de Santa Catarina. Revista Contabilidade \& Finanças. 36, p. 21 - 34, 2004.

RIBEIRO, Maisa; MARTINS, Eliseu. A informação como instrumento de contribuição da contabilidade para a compatibilização no desenvolvimento no envolvimento econômico e a preservação do meio ambiente. Caderno de Estudos da USP. 4-13, 1993.

SALOMONE, Roberta; GALLUCCIO, Giulia. Environmental issues and financial reporting trends: a survey in the chemical and oil \& gas Industries. Working paper: University of Messina. 2001.

SOLOMON, Jill; SOLOMON, Aris. Corporate governance and accountability. London: Willey, 2004.

TINOCO, João. Balanço Social e a contabilidade no Brasil. Caderno de Estudos da USP. 9, p. 1-4, 1993.

TSANG, Eric. A longitudinal study of corporate social reporting in Singapore: the case of the banking, food and beverages and hotel industries. Accounting, Auditing and Accountability Journal. v. 11, p. 624-635, 1998.

VERRECCHIA, Robert. Essays on disclosure. Journal of Accounting and Economics. v. 32, p. 97-180, 2001.

VILLIERS, Charl; STADEN, Chris. Can less environmental disclosure have a legitimizing effect? Evidence from Africa. Accounting, Organization and Society. v. 31, p. 763-781, 2006.

YUSOFF, Haslinda; LEHMAN, Glen; NASIR, Noraini. Environmental engagements through the lens of disclosure practices: a Malaysian story, Asian Review of Accounting. v. 14, p.12248, 2006. 